\title{
Platelet Monoamine Oxidase B Activity in "de novo" and L-Dopa Treated Parkinsonian Patients and Controls
}

\author{
Wilfried Kuhn, Thomas Müller, Anja Gerstner, Regina Winkel \\ and Mario E. Goetz
}

\begin{abstract}
Objective: Previous studies demonstrated controversial results regarding monoamine oxidase B (MAO-B) activity in platelets in the periphery in parkinsonian patients (PD). Subjects and Methods: Therefore we determined platelet MAO-B activity in three age- and sex-matched groups of 17 untreated, so called "de novo" patients with Parkinson's disease (PD), 17 parkinsonian patients, receiving levodopa, and 17 controls by a radio enzymatic assay. Results: No significant differences of MAO-B activity appeared. Conclusion: This result suggests that phenotypic determination of MAO-B activity in platelets may not be used as peripheral marker in PD and that levodopa treatment does not alter MAO-B activity in the periphery.
\end{abstract}

\begin{abstract}
RÉSUMÉ: Activité de la monoamine oxydase B plaquettaire chez les patients naîfs et traités par la L-dopa et chez les contrôles. Objectif: Les résultats des études antérieures concernant l'activité de la monoamine oxydase B (MAO-B) plaquettaire périphérique chez des parkinsoniens (MP) sont controversés. Sujets et méthodes: Nous avons donc mesuré l'activité de la MAO-B plaquettaire par dosage radio-enzymatique chez 3 groupes de 17 patients appariés quant à l'âge et au sexe, soit 17 parkinsoniens jamais traités par la L-dopa, 17 parkinsoniens recevant de la L-dopa et 17 contrôles. Résultat: Il n'y avait pas de différences significatives dans l'activité de la MAO-B. Conclusion: Ce résultat suggère que la détermination de l'activité de la MAO-B plaquettaire ne peut être utilisée comme marqueur du patient dans la MP et que le traitement par la L-dopa ne modifie pas l'activité périphérique de la MAO-B.
\end{abstract}

Can. J. Neurol. Sci. 1998; 25: 249-251

Various enzymes, such as catechol-O-methyl transferase or monoamine oxidase (MAO) metabolise biogenic amines, e.g., dopamine, in the brain. MAO can be differentiated biochemically and pharmacologically into two forms (types A and B) with different substrate specificities and inhibitor sensitivities. Animal studies have indicated that MAO-A is mainly, but not exclusively, located in brain neurons, such as neurons of the locus coerulus, while MAO-B is preferentially found in serotonergic neurons, glia and astrocytes. ${ }^{1.2}$ Elevated levels of MAO-B were found in the substantia nigra of parkinsonian patients. Estimation of peripheral blood cell activities of monoamine oxidase $B$ may reflect central enzyme activity. Therefore platelets were often used as source for MAO-B estimation in the periphery in in vivo studies. ${ }^{3,4}$ MAO-B is potentially relevant to an oxidative stress model of Parkinson's disease (PD) causation, because catabolism of catecholamines via monoamine oxidase B (MAOB) may generate hydrogen peroxide. ${ }^{5}$ Hydrogen peroxide is converted to highly reactive hydroxyl radicals after reaction with transition metals. ${ }^{6}$ Free radical formation and disturbed detoxification processes may be essential contributors to the pathogenesis of Parkinson's Disease (PD).

The aim of this study was to investigate, whether chronic levodopa application may induce changes of MAO-B activity, because enhanced dopamine metabolism might contribute to or even trigger oxidative stress. ${ }^{7}$ We determined platelet MAO-B activity in three age- and sex-matched groups of untreated, socalled "de novo" patients with $\mathrm{PD}$, parkinsonian patients receiving levodopa without further antiparkinsonian medication, and controls.

\section{Material AND Methods}

\section{Subjects}

Seventeen untreated, so called "de novo" idiopathic caucasian parkinsonian patients (mean age: 63.9, SD:10.5, range: 51-83 years, 9 females and 8 males, HYS:1.88 SD: 0.60 , range 1-3), 17 patients with idiopathic PD, only treated with 1dopa/benserazide or carbidopa for at least four weeks without any further antiparkinsonian medication (mean age: 67.4, SD: 8.0; range: 50-77 years; 8 females and 9 males, HYS: 2.76 , SD:

From the Department of Neurology, Ruhr-University of Bochum, St.-Josef Hospital, Bochum, (W.K., T.M., A.G., R.W.); the Department of Neurochemistry, Department of Psychiatry, University of Würzburg, Würzburg, (M.E.G.), Germany. RECEIVED DECEMBER 10, 1997. ACCEPTED IN FINAL FORM MARCH 24, 1998 Reprint requests to: PD Dr. Th. Müller, Department of Neurology, Ruhr-University of Bochum, St.-Josef Hospital, Gudrunstr. 56 D-44791 Bochum, Germany. 
1.25 , range $1-5$, daily levodopa dosage: 338.2 , SD: 164.2 ; range: $75-750 \mathrm{mg}$ ) and 17 controls (mean age: 63.9, SD:10.5; range: 50-83 years, 9 females, 8 males) were enrolled into the study. Selegiline was withdrawn for at least four weeks in subjects treated with selegiline. Subjects taking drugs with a known influence on mitochondrial function or MAO-B activity in platelets, or smokers were excluded.

$125 \mathrm{mg}$ 1-dopa/benserazide or carbidopa was applied at 8 a.m. in treated parkinsonian patients. Blood of all subjects was drawn at $8.30 \mathrm{a} . \mathrm{m}$.

\section{Separation of Blood Platelets}

Preparation of blood platelets was performed according to Koide et al. ${ }^{3} 20 \mathrm{ml}$ of venous blood were collected into $5 \%$ potassium EDTA containing tubes. Platelet-rich plasma (PRP) was prepared by centrifugation at $4^{\circ} \mathrm{C}$ at $170 \mathrm{~g}$ for $20 \mathrm{~min}$ and separated from other blood cells. Platelets were counted in a separated aliquot of the PRP. The remaining PRP was centrifuged at $2700 \mathrm{~g}$ for $15 \mathrm{~min}$, the resulting pellet was resuspended in $500 \mu \mathrm{l} \mathrm{NH} \mathrm{NH}_{4} \mathrm{Cl}(0.87 \%)$. After subsequent centrifugation at $1500 \mathrm{~g}$ for $10 \mathrm{~min}$ the pellet was washed with saline $(0.9 \%)$, resuspended in $500 \mu \mathrm{l} 0.25 \mathrm{M}$ sucrose and frozen at $-70^{\circ} \mathrm{C}$. Prior to performing the radio enzymatic assay the thawed pellet was disrupted by sonication (Bransson Sonifier, $20 \mathrm{kHz}$ ) with a microprobe with five pulses at $5 \mathrm{~W}, 4^{\circ} \mathrm{C}$. The amount of protein was assayed with bovine serum albumin as standard (Bio-Rad, Munich, Germany). ${ }^{8}$

\section{Measurement of Platelet MAO-B Activity}

MAO-B activity in platelets was assayed according to a modified method of Wurtman and Axelrod ${ }^{9}$ and evaluated according to Tipton and Youdim. ${ }^{10}$ Platelets $(500 \mu \mathrm{g}$ protein) were preincubated in $0.1 \mathrm{M}$ phosphate buffer, $\mathrm{pH} 7.4$ (total volume $225 \mu \mathrm{l}$ ) for $7 \mathrm{~min}$ at $37^{\circ} \mathrm{C}$. The reaction was started by addition of $25 \mu \mathrm{l}$ $0.1 \mathrm{M}$ phosphate buffer $\mathrm{pH} 7.4$, containing (1-14 C-ethyl)phenylethylamine (PEA, New England Nuclear, Boston, USA; $100 \mu \mathrm{M}$; specific activity $2.2 \mathrm{GBq} / \mathrm{mmol}$ ). After 7 minutes of incubation $250 \mu \mathrm{l}$ of $1 \mathrm{~N} \mathrm{HCl}$ were added. The acidified solution was extracted with $2 \mathrm{ml}$ of ethyl acetate by shaking for 10 $\min$. The two phases were separated by centrifugation at $1000 \mathrm{~g}$ for $5 \mathrm{~min}$ and $1 \mathrm{ml}$ of the organic phase containing the desaminated metabolites was combined with $4 \mathrm{ml}$ biosolve cocktail (Roth, Karlsruhe, Germany) and counted in a liquid scintillation counter (Beckmann Instruments, Munich, Germany). Recovery of labeled products amounted to $98 \%$ of total radioactivity used. All assays were performed in triplicate. Values were corrected for blank activity. MAO-B activity was measured as pmol of products formed/mg protein/min. PEA was used in a final concentration of $10 \mu \mathrm{M}$ with an activity of $5.2 \mathrm{kBq} /$ assay. Choosing these conditions MAO-B activity was linear with respect to time and protein content.

\section{Statistics}

One-way analysis of variance (ANOVA) was used for comparison of MAO-B activity in all three groups, linear regression $\left(r^{2}\right)$ and Spearman rank analysis ( $\left.r\right)$ for correlations, using the two-tailed approach.

\section{Results}

No significant differences (ANOVA $\mathrm{F}_{(\mathrm{dF} 2, \mathrm{dF} 48)}=0.33, \mathrm{p}=$ 0.72 ) between MAO-B activity of untreated "de novo" parkinsonian patients (mean: $362.4 \mathrm{pmol} / \mathrm{mg} / \mathrm{min}$, SD: 76.5 , range: 269.0-495.2), treated parkinsonian patients (mean: 360.8 $\mathrm{pmol} / \mathrm{mg} / \mathrm{min}, \mathrm{SD}: 94.3$, range: $150.4-516.0$ ) and controls (mean: $384.7 \mathrm{pmol} / \mathrm{mg} / \mathrm{min}, \mathrm{SD}: 111.0$, range: $236.1-612.0$ ) were found (Figure). A significant influence of age in controls $\left(r^{2}=0.267, p=0.033\right)$, "de novo" patients $\left(r^{2}=0.296, p=\right.$ $0.023)$ in contrast to treated parkinsonian patients $\left(\mathrm{r}^{2}=0.103, \mathrm{p}\right.$ $=0.208$ ) appeared. No association between HYS score and MAO-B activity appeared in treated $(r=0.412, p=0.11)$ and "de novo" $(r=0.38, p=0.123)$ parkinsonian subjects. No influence of sex was found.

\section{Discussion}

Previous studies on MAO-B activity in platelets in parkinsonian patients and controls showed controversial results. Mann et al. ${ }^{11}$ found no differences. Zeller et al. ${ }^{12}$ indicated lower (not significant) MAO-B activity in $\mathrm{PD}$, using tyramine as substrate. Significantly increased activity of MAO-B in untreated ${ }^{13-15}$ and treated (mainly levodopa/benserazide and amantadine sulfate) parkinsonian patients ${ }^{16}$ were found, measuring with phenylethylamine (PEA). With dopamine and kynuramine significant reductions of MAO-B activity in untreated parkinsonian patients were demonstrated. ${ }^{17-20}$ Therefore one has speculated, that the number of hydroxyl groups of the used substrate might influence the estimation of peripheral MAO-B activity. Nevertheless the controversial results of peripheral enzyme MAO-B activity in PD were also referred to the different genotypes of MAO-B, because they may cause altered affinities for the used substrates of the assay and/or they may appear in different frequencies in various populations. ${ }^{12-14,17-20}$ Studies on the frequency of MAO$B$ genotypes also showed controversial results. A polymorphism in intron 13 of the MAO-B gene was identified and it was speculated that one allele occurs more frequent in PD compared to controls. ${ }^{21}$ Significantly different frequencies of allelic polymorphisms of the MAO-B appeared in PD. ${ }^{22}$ However a more recent study did not confirm this result. ${ }^{23}$

In our study untreated, "de novo" and only levodopa treated caucasian ${ }^{1-23}$ parkinsonian patients were included in order to

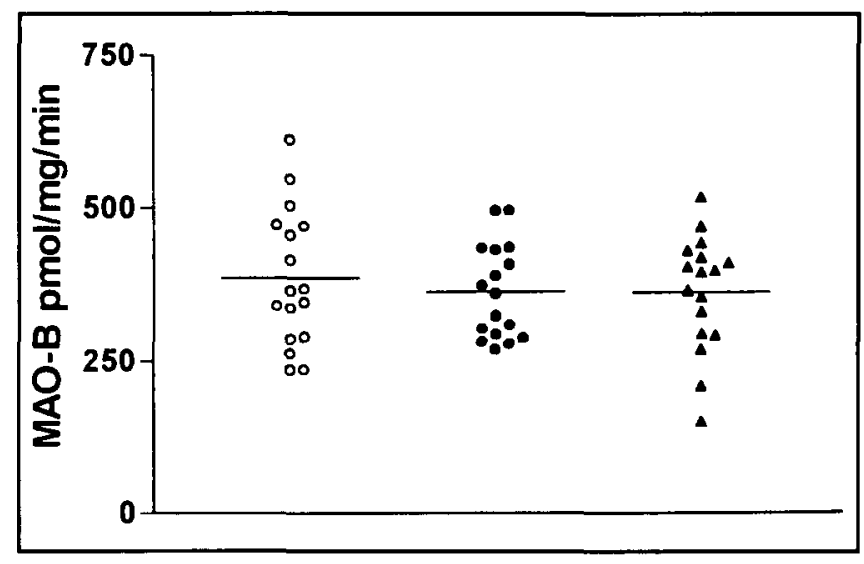

Figure: Legend MAO-B enzyme activity values of (O controls, $\bullet$ "de novo" and $\mathbf{A}$ levodopa-treated parkinsonian patients, - mean value. 
demonstrate possible effects of levodopa therapy on peripheral MAO-B activity. No significant differences of MAO-B activity appeared in all three investigated groups in this study. This implies as well, that various genotypes of MAO-B have no essential effect on MAO-B enzyme activity.

According to our results, chronic levodopa application does not essentially affect peripheral MAO-B activity. But due to the positive correlation with age in controls and "de novo" parkinsonian patients in contrast to the lack of association with age in the case of levodopa treated parkinsonian patients, one may speculate that a slight effect of levodopa on MAO-B activity may be responsible for this lack of association.

In conclusion we postulate, that platelet MAO-B enzyme activity is not a marker for $\mathrm{PD}$, and is not affected by levodopa therapy. The discussed overrepresentation of one genotype of the MAO-B enzyme in $\mathrm{PD}^{21-23}$ might not influence peripheral phenotypic enzyme activity of MAO-B.

\section{REFERENCES}

1. Riederer P, Konradi C, Schay V, et al. Localization of MAO-A and $\mathrm{MAO}-\mathrm{B}$ in human brain: a step in understanding the therapeutic action of L-deprenyl. Adv Neurol 1987; 45: 111-118.

2. Konradi C, Riederer P, Jellinger K, Denney R. Cellular action of MAO inhibitors. J Neural Transm Suppl 1987; 25: 15-25.

3. Koide. Y, Koide N, Ross S, Sääf J, Wetterberg L. Monoamine oxidase in human platelets. Kinetics and methodological aspects. Biochem Pharmacol 1981; 30: 2893-2900.

4. Checkoway H, Costa LG, Woods JS, et al. Peripheral blood cell activities of monoamine oxidase $B$ and superoxide dismutase in Parkinson's disease. J Neural Transm Park Dis Dement Sect 1992; 4: 283-290.

5. Cohen G. Monoamine oxidase, hydrogen peroxide, and Parkinson's Disease. In: Yahr MD, Bergmann KJ, eds. Advances in Neurology. New York: Raven Press, Vol 45; 1986: 119-125.

6. Halliwell B. Free radicals, antioxidants, and human disease: curiosity, cause, or consequence? Lancet 1994; 344: 721.

7. Riederer P, Konradi C, Hebenstreit G, Youdim MBH. Neurochemical perspectives to the function of monoamine oxidase. Acta Neurol Scand 1989; 80 (Suppl 126): 41-45.

8. Bradford MM. A rapid and sensitive method for the quantification of microgram quantities of protein utilizing the principle of protein-dye binding. Anal Biochem 1976;72: 248-254.

9. Wurtman RJ, Axelrod J. A sensitive and specific assay for the estimation of monoamine oxidase. Biochem Pharmacol 1963; 12: 1439-1441.
10. Tipton KF, Youdim MBH. The assay of monoamine oxidase. $l n$ Parvez S, Nagatsu T, Nagatsu I, Parvez H, eds. Methods Biogenic Amine Res, Amsterdam: Elsevier, 1983: 441-465.

11. Mann JJ, Stanley M, Kaplan RD, Sweeney J, Neophytides A. Central catecholamine metabolism in vivo and the cognitive and motor deficits in Parkinson's disease. J Neurol Neurosurg Psychiatry $1983 ; 46$ : 905-910.

12. Zeller EA, Boshes B, Arbit J, et al. Molecular biology of neurological and psychiatric disorders. I. Effects of Parkinsonism, age, sex, and L-Dopa on platelet monoamine oxidase. J Neural Transm 1976; 176; 39: 63-77.

13. Steventon GB, Sturman SG, Heafield MTE, et al. Platelet monoamine oxidase B in Parkinson's Disease. J Neural Transm PD Sect 1989; $1: 255-261$.

14. Jarman J, Glover V, Sandler M, Turjanski N, Stern G. Platelet monoamine oxidase B activity in Parkinson's Disease: a reevaluation. J Neural Transm PD Sect 1993; 5: 1-4.

15. Sandler M, Glover V, Clow A, Jarman J. Monoamine oxidase-B inhibitors and Parkinson's disease. A role for superoxide dismutase? In: Narabayashi H, Nagatsu T, Yanagisawa N, Mizuno Y, eds. Advances in Neurology, New York: Raven Press, 1993 238-241.

16. Lee DH, Mendoza M, Dvorozniak MT, et al. Platelet monoamine oxidase in Parkinson patients: effect of l-deprenyl therapy. J Neural Transm PD Sect 1989; 1: 189-194.

17. Danielczyk W, Streifler M, Konradi C, Riederer P, Moll G. Platelet MAO-B activity and the psychopathology of Parkinson's disease, senile dementia and multiinfarct dementia. Acta Psychiatr Scand 1988; 78: 730-736.

18. Humfrey CDN, Steventon G.B, Sturman SG, et al. Monoamine oxidase substrates in Parkinson's disease. Biochem Pharmacol 1990; 40: 2562-2564.

19. Steventon G, Humfrey C, Sturman S, Waring RH, Williams AC. Monoamine oxidase B and Parkinson's disease. Lancet 1990; 20: 180.

20. Kuiper MA, Konings $\mathrm{CH}$, Bergmans PLM, Wolters E Ch. Monoamine oxidase-B activity in untreated and treated Parkinson patients. In: Abstracts of the 10th International Symposium on Parkinson's disease, 1991; Tokyo: 182.

21. Kurth JH, Kurth MC, Poduslo SE, Schankhaus JD. Association of a monoamine oxidase B allele with Parkinson's disease. Ann Neurol 1993; 33: 368-372.

22. Hotamisligil GS, Girmen AS, Fink JS, et al. Hereditary variations in monoamine oxidase as a risk factor for Parkinson's Disease. Mov Disord 1994; 9: 305-310.

23. Ho SL, Kapadi L, Ramsden DB, Williams AC. An allelic association study of monoamine oxidase B in Parkinson's disease. Ann Neurol 1995; 37: 403-405. 